\section{Commentary: For unusual cases, preparation is key}

\author{
Alison F. Ward, MD, and Richard Lee, MD, MBA
}

In this edition of the Journal, Albacker and colleagues ${ }^{1}$ describe a case of left main and left anterior descending coronary artery ectasia fistulizing to the right ventricle in a 28-year-old female patient. The patient was initially diagnosed with an apical ventricular septal defect on transthoracic echocardiography, but intraoperatively the anomalies were identified and the fistula was closed with a bovine pericardial patch from the right ventricular side. Postoperatively, the patient was anticoagulated and repeat imaging 2 years later demonstrated no residual shunt and stable-sized coronary arteries.

The authors were surprised on their initial intraoperative inspection when they saw ectatic coronary arteries and communication of the presumed ventricular septal defect with the distal coronary artery. They elected not to address the ectatic coronary artery in the operating room because they did not know the full coronary anatomy. Preoperative left heart catheterization would be unusual to perform on this young patient and hindsight is $20 / 20$, but with congenital heart disease presenting in a 28 -year-old patient, the authors should have considered cardiac magnetic resonance imaging. This could have provided a better "roadmap" with which to work and would likely have prompted a left heart catheterization, allowing them to address the coronary anomaly at the time of the initial operation.

It is interesting that a left heart catheterization was not performed immediately after surgery, which would have allowed a more immediate intervention based on the findings.

\footnotetext{
From the Division of Cardiothoracic Surgery, Department of Surgery, Medical College of Georgia, Augusta University, Augusta, Ga.

Disclosures: The authors reported no conflicts of interest.

The Journal policy requires editors and reviewers to disclose conflicts of interest and to decline handling or reviewing manuscripts for which they may have a conflict of interest. The editors and reviewers of this article have no conflicts of interest.

Received for publication Feb 27, 2020; revisions received Feb 27, 2020; accepted for publication Feb 28, 2020; available ahead of print March 5, 2020.

Address for reprints: Richard Lee, MD, MBA, Department of Surgery, Medical College of Georgia, 1120 15th St, BA-4300, Augusta, GA 30912 (E-mail: richardleemdmba@gmail.com).

JTCVS Techniques 2020;2:73-4

2666-2507

Copyright (C) 2020 The Authors. Published by Elsevier Inc. on behalf of The American Association for Thoracic Surgery. This is an open access article under the CC BY-NCND license (http://creativecommons.org/licenses/by-nc-nd/4.0/).

https://doi.org/10.1016/j.xjtc.2020.02.030
}

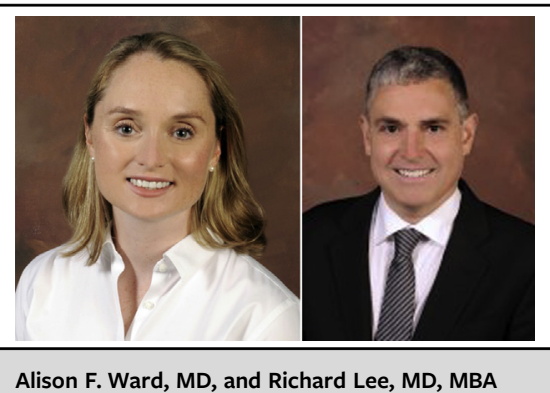

Alison F. Ward, MD, and Richard Lee, MD, MBA

CENTRAL MESSAGE

Coronary artery ectasia and fis-

tula to the right ventricle is a rare and complex disease; a thorough

preoperative workup can aid in

the optimal surgical manage-

ment of these patients.

Although the operation was likely not performed in a hybrid operating room, a trip to the catheterization laboratory could have been considered immediately postoperatively, given such unusual intraoperative findings. Instead, before discharge, the patient underwent left heart catheterization, demonstrating significant coronary artery ectasia of the left main and left anterior descending. The authors chose to forego additional coronary interventions because of its diffuse pattern, and instead they started the patient on lifelong anticoagulation for prevention of thrombotic complications. Lifelong antiplatelet therapy and anticoagulation have both been described in several case series. ${ }^{2-4}$ Our concern with this approach in a woman of child-bearing age is the need for lifelong anticoagulation, and perhaps antiplatelet therapy would be more appropriate in this patient.

Another concern of ours is the patient's untreated coronary dilatation. The size of the coronary dilatation is not detailed in this manuscript, but based on the angiography and computed tomography images, it approaches several centimeters, placing this patient at risk for significant complications, including thrombosis and rupture. The ideal management of significant coronary dilatation is not known, but interventions including reduction aneurysmectomy using Teflon felt strips to plicate the artery or even ligation and distal bypass have been described. ${ }^{4,5}$ Despite the stability in size of her coronary arteries on 2-year computed tomography scan, she remains at risk for adverse events and will likely need to have the coronary ectasia addressed in the future. 
The authors should be congratulated on identifying this complex and rare problem and effectively treating it with an excellent outcome. This underscores the importance of effective preoperative planning and creative solutions when confronted with intraoperative surprises.

\section{References}

1. Albacker TB, Barghouthi R, Zahran F, Aljerayed N. Surgical treatment of left main and left anterior descending artery ectasia with fistula to right ventricle. $J$ Thorac Cardiovasc Surg Tech. 2020;2:70-2.
2. Damay V, Pranata R, Wiharja W. Recurrent acute coronary syndrome in a patient with right coronary artery ectasia: a case report. J Med Case Rep. 2019; 13:78.

3. Hou B, Ma WG, Zhang J, Du M, Sun HS, Xu JP, et al. Surgical management of left circumflex coronary artery fistula: a 25-year single-center experience in 29 patients. Ann Thorac Surg. 2014;97:530-6.

4. Yuxiang D, Feng Z, Juying Q, Junbo G. Thrombotic occlusion and revascularization of a left main coronary artery aneurysm years after surgical closure of left coronary-to-right ventricle fistula. JACC Cardiovasc Interv. 2018; 11:314-5.

5. Murakami M, Gohra H, Yagi T, Jinbou M, Kobayashi T, Saito S, et al. Surgical procedure for coronary artery ectasia associated with saccular fistula. Heart Lung Circ. 2014;23:e181-3. 